\title{
MÚSICA, SAÚDE E BEM-ESTAR: AULAS DE MÚSICA E HABILIDADES COGNITIVAS NÃO
} MUSICAIS

\author{
Music, health and well-being: music \\ lessons and nonmusical cognitive \\ abilities
}

\author{
Música, salud y bienestar: las clases de \\ música y las habilidades cognitivas no \\ musicales
}

\author{
JosÉ DAVISON DA SILVA JÚNIOR \\ Universidade Federal de Minas Gerais \\ davisonjr@gmail.com
}

\begin{abstract}
Resumo: Este artigo apresenta o tema Música, saúde e bem-estar e suas áreas, musicoterapia, música comunitária, uso da música no dia a dia, música na medicina e educação musical. Destacamos a educação musical, cujo objetivo primário é o ensino de música, mas que também pode alcançar objetivos secundários, como melhora em habilidades cognitivas não musicais, tais como a percepção da fala, outras habilidades de linguagem, habilidades espaciais, habilidades matemática, QI e sucesso acadêmico, memória e funcionamento executivo. Apesar de alguns estudos correlacionais e experimentais mostrarem resultados positivos, ainda não está clara a relação entre aulas de música e habilidades cognitivas não musicais, bem como a transferência do domínio musical para outros dominios, e que estudos correlacionais não implicam relação de causalidade. Sendo assim, é necessário cautela antes de justificarmos o ensino de música pelos beneficios nas habilidades cognitivas não musicais.
\end{abstract}

Palavras-chave: Música, saúde e bem-estar. Aulas de música. Habilidades cognitivas não musicais.

\begin{abstract}
This article presents the theme Music, Health and Wellbeing and its areas: music therapy, community music, everyday uses of music, music medicine and music education. We emphasize musical education, whose primary purpose is teaching music, but can also achieve secondary goals, such as improvement in nonmusical cognitive abilities, such as speech perception, other language skills, spatial abilities, mathematical skills, IQ and academic success, memory, and executive functioning. Although some correlational and experimental studies show positive results, the relationship between music classes and nonmusical cognitive abilities is still unclear, as well as the transfer of the musical domain to other domains and that correlational studies do not imply causal relationship. Therefore, caution is needed before we justify the teaching of music by the benefits of non-musical cognitive abilities.
\end{abstract}

Keywords: Music, health and wellbeing. Music lessons. Nonmusical cognitive abilities.

Resumen: Este artículo presenta el tema de la música, la salud y el bienestar y sus áreas, musicoterapia, música comunitaria, uso de la música en el día a día, la música en la medicina y la educación musical. Destacamos la educación musical, cuyo objetivo principal es la enseñanza de la música, pero también que puede lograr objetivos secundarios, tales como la mejora de las habilidades cognitivas no musicales, tales como la percepción del habla, otras habilidades del lenguaje, habilidades espaciales, las matemáticas, el QI y el éxito académico, la memoria y el funcionamiento ejecutivo. Aunque algunos estudios correlativos y estudios experimentales muestran resultados positivos, todavia no está clara la relación entre las clases de música y las habilidades cognitivas no musicales, asi como la trasferencia del domínio musical para otras zonas, y que los estudios correlativos no implican una relación causal. Por lo tanto, es necesario tomar precauciones antes de justificar la enseñanza de música por los benefícios en las habilidades cognitivas no musicales.

Palabras clave: Música, salud y bienestar. Lecciones de música. habilidades cognitivas no musicales. 


\section{INTRODUÇÃO}

A relação entre música, saúde e bem-estar é complexa, multifacetada e envolve uma questão central: Por que a música tem produzido benefícios em diferentes contextos? Um grande desafio é estabelecer uma relação causal entre atividades musicais e beneficios na saúde e no bem-estar. Existem algumas possiveis razões pelas quais a música pode produzir efeitos positivos na saúde, tais como: a música é ubiqua, emocional, envolvente, distrai, gera uma demanda física, é ambígua, social, comunicativa, afeta o comportamento e a identidade (MacDonald; Kreutz; Mitchell, 2012).

Existem cinco áreas nas quais as pesquisas sobre música, saúde e bemestar concentram-se para verificar os beneficios da música nos sujeitos que estão inseridos nesses contextos. São elas: musicoterapia, música comunitária, uso da música no dia a dia, música na medicina e educação musical. Em cada uma dessas áreas, os beneficios da música serão buscados como objetivo primário ou secundário.

Segundo Hentschke e Del Ben (2003, p. 181), “o objetivo primeiro da educação musical é facilitar o acesso à multiplicidade de manifestações musicais de nossa cultura, bem como possibilitar a compreensão de manifestações musicais de culturas mais distantes". Porém, o engajamento com a música também pode trazer beneficios não musicais.

Creech et al. (2013) afirmam que o fazer musical tem fornecido uma base para o aumento da coesão social, do prazer, do desenvolvimento pessoal, além de contribuir para a recuperação da depressão e manutenção do bem-estar entre idosos. Hallam (2010) comenta que um objetivo recorrente da educação musical é facilitar oportunidades para autoexpressão, permitindo que os individuos expressem suas próprias emoções, sentimentos e identidade por meio da música. Esse objetivo pode ser encontrado através da composição, improvisação ou interpretação da música criada por outros. Dabback et al. (2012) destacam a relação entre o envolvimento direto com a música, a memória e a identidade.

Dentre os benefícios alcançados com as aulas de música, há um maior destaque para o alcance de habilidades cognitivas não musicais, as quais se referem aos aspectos da cognição que não estão diretamente relacionados a conteúdo ou conhecimentos musicais, como memória, linguagem, habilidades visuoespaciais e inteligência (Schellenberg; Weiss, 2013). Segundo Schellenberg (2016), os estudos sobre aulas de música e habilidade cognitivas não musicais podem ser organizados em habilidades cognitivas específicas (percepção da fala, outras habilidades de linguagem, habilidades espaciais, habilidades matemáticas) e habilidades cognitivas gerais (QI e sucesso acadêmico, memória e funcionamento executivo).

Swaminathan e Schelleberg (2018) alertam que ainda não está clara a relação entre aulas de música e habilidades não musicais, bem como a 
transferência do domínio musical para outros domínios. Os autores destacam que a correlação entre aulas de música e habilidades não musicais não implica uma causa. Por isso, precisamos ter cautela antes de afirmarmos que uma criança é mais inteligente que outra porque estuda música.

\section{MÚSICA, SAÚDE E BEM-ESTAR: QUADRO CONCEITUAL}

O quadro conceitual para música, saúde e bem-estar foi apresentado por MacDonald (2013), na tentativa de integrar cinco áreas que podem utilizar a música em razão de seus resultados positivos. Ele foi desenvolvido com o objetivo de aumentar o diálogo multidisciplinar dentre vários profissionais que estão envolvidos em investigar a relação entre participação musical e parâmetros de saúde mais amplos. As áreas são: musicoterapia, música comunitária, uso da música no dia a dia, música na medicina e educação musical. Elas não estão isoladas, mas têm interfaces umas com as outras, como pode ser visto na figura abaixo.

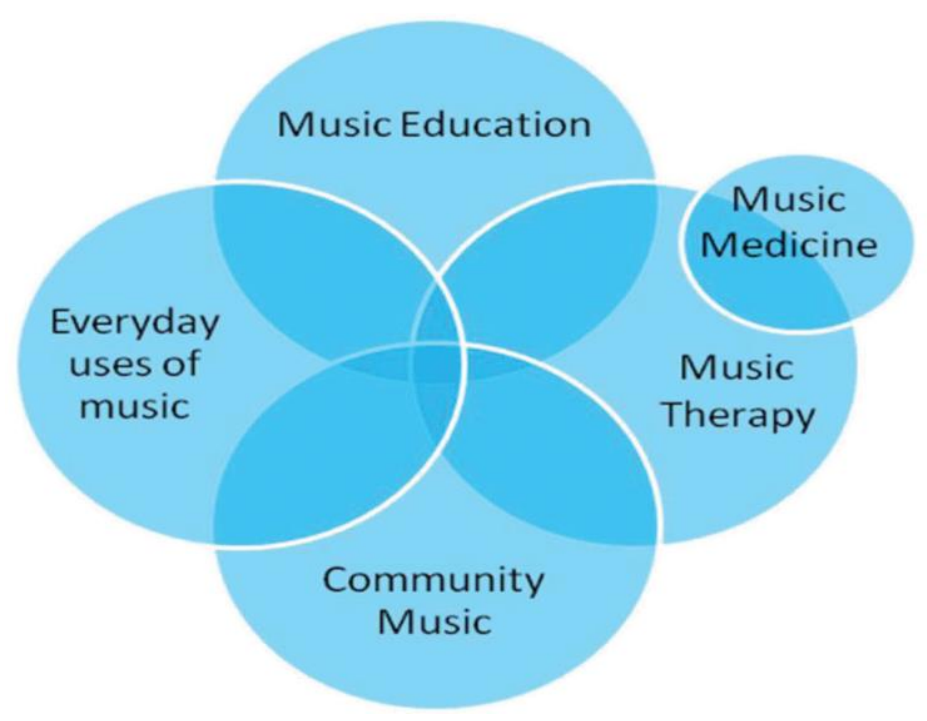

Figura 1: Quadro conceitual para música, saúde e bem-estar (MacDonald, 2013, p. 2).

A primeira área é a musicoterapia, cujo berço foi a Primeira Guerra Mundial, onde a música foi utilizada nos hospitais dos Estados Unidos por músicos profissionais, após comprovação do efeito relaxante e sedativo produzidos pela audição musical nos doentes de guerra, e na Segunda Guerra Mundial, onde a música foi utilizada para recuperação de neuróticos de guerra (Leining, 1977; Moura Costa, 1989).

A musicoterapia pode ser definida de diversas maneiras. Porém, o aspecto mais importante é a ênfase na relação terapêutica entre o cliente e o musicoterapeuta, utilizando a música como o principal meio para estabelecer e manter essa relação, bem como produzir benefícios positivos para o cliente. As intervenções musicoterapêuticas priorizam os beneficios psicológicos ou 
fisiológicos dos clientes como objetivo primário e serão realizadas por musicoterapeutas qualificados. O objetivo das intervenções não será o desenvolvimento musical, em termos de aumento de habilidades técnicas, e também não há preocupação com o aumento geral das atividades artísticas no domínio musical. Pelo fato de ser a área que sempre terá objetivos terapêuticos, a musicoterapia tem interfaces com todas as outras áreas (MacDonald; Kreutz; Mitchell, 2012; MacDonald, 2013).

A segunda área é a música comunitária, que pode ser definida como uma intervenção musical que ocorre fora do contexto formal da educação. Uma das formas mais populares da música comunitária é o coro comunitário. A música comunitária não terá os efeitos terapêuticos como objetivo primário, mas, sim, o acesso às atividades artísticas fora de contextos convencionais de ensino. O objetivo primário pode ser oferecer uma oportunidade para a expressão criativa em contextos não formais (MacDonald, 2013).

Algumas vezes as intervenções da música comunitária podem ter benefícios psicológicos como objetivo secundário, como quando são oferecidas aulas de música em hospital psiquiátrico, por exemplo. Aqui a ênfase é no desenvolvimento de habilidades específicas, mas a intervenção, que é social e agradável, pode gerar benefícios não musicais, ilustrando como a música comunitária tem interface com a musicoterapia e a educação musical e também com a escuta musical no dia a dia (MacDonald; Kreutz; Mitchell, 2012; MacDonald, 2013).

O uso da música no dia a dia não é um campo distinto de prática, como a educação musical e a música comunitária. Todavia, o uso da música no dia a dia tem relevância sobre os efeitos da música na saúde e no bem-estar. A discussão sobre como ouvir música pode produzir efeitos positivos em nossa saúde e bem-estar gera um reconhecimento que esta é uma importante área de estudo (MacDonald, 2013).

Cada vez que selecionamos uma música para ouvir, estamos fazendo muitas avaliações sobre nosso estado mental e sobre o ambiente em que iremos escutar música. Dessa forma, nós reconhecemos que nossa escuta musical tem efeitos profundos sobre como nós nos sentimos e também afeta as outras pessoas que podem estar escutando nossa seleção musical. Essa situação musical não é explicitamente terapêutica, clínica ou educacional, mas tem importância em como pode afetar positivamente a saúde e o bemestar, tendo relações com a educação musical, a musicoterapia e a música comunitária (MacDonald; Kreutz; Mitchell, 2012; MacDonald, 2013).

A quarta área é a música na medicina, a qual é uma área especializada da música, saúde e bem-estar que ocorre em contextos médicos. Um exemplo típico ocorre quando um paciente escuta música durante o procedimento cirúrgico, para ajudar a reduzir a percepção da dor e a ansiedade. A música na medicina é aplicada na cirurgia, anestesia, odontologia, dor, cuidado paliativo, obstetrícia, pediatria, geriatria, oftalmologia, dentre outras 
(MacDonald, 2013). A música na medicina também pode ser a utilização da música pelos diversos profissionais da saúde, além do médico.

Existem diferenças entre a música na medicina ou em medicina e a musicoterapia em medicina. Dileo (apud Barcellos, 2016) caracteriza a musicoterapia em medicina como aquela realizada por musicoterapeutas qualificados que utilizam métodos e técnicas específicos em musicoterapia, envolvendo sempre um processo terapêutico. Já a música em medicina é realizada por profissionais da área médica que não são musicoterapeutas, como terapia complementar; a relação terapêutica entre o paciente e a equipe médica envolvida não se desenvolve através da música.

Bruscia (2000) faz a distinção entre música como terapia e música na terapia. Na música como terapia, a música exerce uma influência direta sobre o cliente, e sua saúde e serve como agente primário na mudança terapêutica, enquanto na música na terapia a música não é o agente primário ou o único agente da mudança, e sua utilização depende do terapeuta. A música como terapia é a forma de utilização da música na musicoterapia. A música na terapia é a forma de utilização da música por outros profissionais da saúde, os quais não possuem formação em musicoterapia

A música na medicina não tem relação com educação musical, música comunitária ou música no dia a dia, mas se relaciona somente com a musicoterapia, pois tem os benefícios psicológicos ou fisiológicos como objetivo primário. Outro aspecto importante é que a maioria das intervenções da música na medicina utiliza música gravada e pré-selecionada (MacDonald, 2013).

A educação musical é outro elemento-chave no quadro conceitual do tema Música, saúde e bem-estar. Em muitos contextos, a educação musical é definida por uma ênfase no desenvolvimento de habilidades musicais convencionais. Por exemplo, muitas aulas de música em escolas e universidades enfatizam o desenvolvimento da técnica instrumental ou conhecimentos técnicos específicos. Pesquisadores têm investigado os efeitos de aulas de música convencionais em outros aspectos não musicais do funcionamento psicológico, e aqui existe uma sobreposição com a musicoterapia e com a música comunitária (MacDonald, 2013).

Barcellos (2016) destaca que tanto a educação musical quanto a musicoterapia utilizam música e podem vir a ter efeitos terapêuticos, mas a única que tem objetivos terapêuticos e se constitui como terapia é a musicoterapia. Segundo a autora, "há uma grande diferença em se ter objetivos terapêuticos ou em uma utilização que tenha efeitos terapêuticos sem que o trabalho tenha o objetivo de ser terapêutico" (Barcellos, 2016, p. 209).

Há bastante interesse na possibilidade de a educação musical produzir benefícios em habilidades não musicais. Por exemplo, questiona-se se ter aulas de piano aumenta o desempenho na matemática ou se as aulas de 
violino aumentam as capacidades cognitivas gerais. O ponto-chave aqui é que essas intervenções não têm como objetivo primário o alcance de benefícios psicológicos. O objetivo das aulas de piano é aumentar a habilidade no piano, mas existem beneficios secundários para os participantes (MacDonald, 2013). O principal tema da educação musical relacionado à saúde e ao bem-estar são as habilidades cognitivas não musicais alcançadas com as aulas de música.

\section{AULAS DE MÚSICA E HABILIDADES COGNITIVAS NÃO MUSICAIS}

De acordo com Schellenberg e Weiss (2013), o termo habilidades cognitivas ou habilidades não musicais refere-se a todos os aspectos da cognição que não estão diretamente relacionados a conteúdo ou conhecimentos musicais, tais como memória, linguagem, habilidades espaciais e inteligência em geral. Os estudos sobre música e habilidades não musicais são organizados em quatro categorias: 1) aptidão musical e habilidades cognitivas; 2) habilidades cognitivas depois da audição musical; 3) música de fundo e habilidades cognitivas; 4) aulas de música e habilidades cognitivas. Nossa ênfase será nesta última categoria.

Williamson (2014) destaca duas importantes questões a serem observadas ao estudar o tema aulas de música e habilidades cognitivas não musicais. A primeira questão é que não existe uma definição consistente de músico na literatura, pois muitos estudos incluem pessoas com diferentes experiências e tempos de formação musical. Geralmente, quando se fala em músico, refere-se a alguém que estudou música por, pelo menos, dez anos.

A segunda questão é que, muitas vezes, não é possivel afirmar que as aulas de música causem alguma mudança em alguma habilidade cognitiva específica. Pode existir alguma diferença individual antes do início do estudo musical. A maioria dos estudos realizados sobre aulas de música e habilidades cognitivas não mostra uma relação de causalidade.

De acordo com Swaminathan e Schellenberg (2018), estudos correlacionais e experimentais (como, por exemplo, Herholz; Zatorre, 2012; Münte; Altenmüller; Jäncke, 2002; Wan; Schlaug, 2010) têm proposto que as aulas de música são o modelo perfeito para investigar a plasticidade e a transferência de aprendizagem. Consequentemente, as correlações entre aulas de música e habilidades não musicais seriam suficientes para fornecer evidência sobre as relações de causalidade. Entretanto, essa tendência é problemática por três razões.

A primeira razão é que a relação entre aulas de música e habilidades não musicais não é clara. Por exemplo, às vezes os experimentos falham em documentar melhorias nas habilidades cognitivas depois de aulas de música. Os estudos que mostram melhoria muitas vezes adotam pedagogias não padronizadas, como o desenvolvimento de habilidade de ouvir música, ao invés de ensinar os participantes a cantar ou tocar um instrumento musical. 
Quando as crianças estão inseridas em um contexto do modelo tradicional, sem custo para seus pais, o processo de aprendizagem tem pouca semelhança com o mundo real, pois geralmente os pais não insistem que seus filhos pratiquem entre as aulas.

A segunda razão é mais teórica e diz respeito à interface entre correlação e causa. A correlação não implica causa. Se as aulas de música provocam melhorias nas habilidades cognitivas, deve-se esperar que este efeito seja percebido na vida cotidiana, de modo que os individuos que receberam as aulas de música exibam os efeitos positivos documentados.

A terceira razão envolve a transferência de domínios, ou seja, se a música leva a um melhor desempenho ou aprendizagem mais rápida em um domínio diferente, não musical. Apesar de mais de um século de pesquisa, ainda não está claro se os efeitos de transferência são mesmo possiveis.

Schellenberg (2016) sistematizou as principais descobertas sobre as associações entre aulas de música e habilidades não musicais, as quais foram organizadas em: 1) habilidades cognitivas específicas (percepção da fala, outras habilidades de linguagem, habilidades espaciais, habilidades matemáticas); e 2) habilidades cognitivas gerais (QI e sucesso acadêmico, memória e funcionamento executivo). Apresentaremos alguns aspectos desses dois pontos: aulas de música e habilidades cognitivas específicas e aulas de música e habilidades cognitivas gerais.

\section{1) Aulas de música e habilidades cognitivas específicas}

As habilidades cognitivas específicas discutem a relação entre as aulas de música e o desempenho em domínios específicos, como a percepção da fala, outras habilidades de linguagem, habilidades espaciais e habilidades matemáticas. Com relação à percepção da fala, Strait e Kraus (2014) verificaram que músicos têm melhor desempenho em tarefas de percepção da fala, por causa do aumento nas redes neurais relacionadas à audição, quando comparados com não músicos. Até mesmo crianças com 9 anos de idade que tiveram aulas de música foram melhores em testes de processamento da frequência e discriminação da altura dos sons da fala do que crianças sem aulas de música (Chobert et al., 2011).

Schellenberg (2016) questiona o papel da aptidão musical quando alguém apresenta um melhor desempenho na percepção da fala depois de receber aulas de música, ou seja, o autor questiona se alguma habilidade musical presente desde o nascimento pode ter alguma influência no melhor desempenho da percepção da fala de quem teve aulas de música.

Os testes de aptidão servem para determinar quem poderia se beneficiar das aulas música, partindo do pressuposto de que crianças com alta aptidão poderiam se beneficiar mais do que crianças com baixa aptidão. Se considerarmos que crianças com alto nivel de aptidão musical têm uma maior probabilidade de ter aulas de música, isso poderia implicar considerar que a 
aptidão musical também teria influência nos resultados de testes de percepção da fala.

Embora seja razoável afirmar que as aulas de música aumentam as habilidades de escuta em geral e as habilidades da percepção da fala em particular, existe pouca evidência a esse respeito. É possivel que as aulas de música fortaleçam diferenças que já existiam em alguém, mostrando uma interação entre algo inato e algo adquirido, entre o genético e o ambiente.

Apesar de resultados de pesquisas (como Berck, 2012; Strait; Krauss, 2011 apud Schellenberg, 2016) mostrarem um melhor desempenho na acuidade e na percepção da fala de quem tem mais tempo de treinamento musical, pessoas que possuem um alto nível de aptidão musical poderiam ser mais propensas a terem aulas de música por mais tempo, e por isso teriam um melhor desempenho em testes de percepção da fala (Schellenberg, 2016).

Além dos testes de percepção da fala, individuos que receberam aulas de música têm um melhor desempenho em testes de outras habilidades de linguagem. Por exemplo, músicos geralmente têm um melhor desempenho na memória verbal, como em testes para lembrar uma lista de palavras que foram lidas anteriormente. Isso provavelmente ocorre devido às mudanças na estrutura do cérebro dos músicos, quando comparados com não músicos (Brandler; Rammsayer, 2003). Crianças que receberam aulas de instrumento musical por três anos, pelo menos, mostraram um melhor desempenho na discriminação auditiva e aumento de vocabulário quando comparadas com outras crianças que não receberam as aulas (Forgeard et al., 2008).

Existem muitas associações entre aulas de música e habilidades de linguagem, embora muitas dessas associações possam ocorrer devido às diferenças individuais na aptidão musical ou na habilidade cognitiva geral. Há alguma evidência de que aulas de música aumentem o vocabulário e as habilidades necessárias para a leitura.

Entretanto, pelo fato de as intervenções durante a pesquisa serem quase diárias e de as condições da pesquisa serem bem específicas, não está claro se os resultados dos estudos poderiam ser generalizados para outras situações de aprendizagem musical ou para outras medidas de habilidade de linguagem (Schellenberg, 2016).

Habilidade espacial é a capacidade de manipular mentalmente uma imagem visual na ausência de um modelo físico. Rauscher e Hinton (2011) mostraram que houve melhora no desempenho em testes de habilidade espacial em crianças que receberam aulas de música, e esse efeito durou por dois anos. Schelleberg (2016) afirma que os estudos mostram uma associação positiva entre aulas de música e habilidades espaciais. Todavia, essa evidência não exclui a possibilidade de crianças com boas habilidades espaciais serem mais propensas a terem aulas de música do que outras crianças cujas habilidades espaciais não sejam tão boas. 
A relação entre aprendizagem musical e habilidades matemáticas gera um interesse particular porque muitas propriedades da música são baseadas em relações matemáticas, o que levanta a hipótese de que aulas de música poderiam ajudar no aprendizado da matemática. Para investigar a hipótese de que matemáticos têm um melhor desempenho musical do que não matemáticos, Haimson, Swain e Winner (2011) aplicaram um questionário entre membros da Associação Americana de Matemática e da Associação de Linguas Modernas. O grupo de matemáticos não mostrou altos niveis de musicalidade, o que não comprovou a hipótese de que matemáticos são mais musicais do que pessoas com outros conhecimentos não quantitativos.

Segundo Schellenberg (2016), não existem evidências consistentes que façam associações entre aulas de música e habilidades matemáticas ou que mostrem uma relação de causalidade entre melhor desempenho na matemática devido às aulas de música. Quando tais associações são feitas, elas poderiam acontecer pelo fato de individuos com alto funcionamento cognitivo serem mais propensos a terem aulas de música e, assim, terem um melhor desempenho em testes de matemática.

\section{2) Aulas de música e habilidades cognitivas gerais}

Há evidências de que aulas de música causam pequenos aumentos no QI. No estudo experimental realizado por Schellenberg (2004), 144 crianças de seis anos de idade foram divididas, durante um ano e de forma aleatória, em quatro grupos: 1) aulas de teclado; 2) aulas de canto; 3) aulas de teatro; 4) sem nenhuma aula (de teclado, canto ou teatro). Antes e depois da intervenção foi aplicado o teste de inteligência (Wechsler Intelligence Scale for Children - Third Edition).

No começo do estudo realizado por Schellenberg (2004) não havia nenhuma diferença de QI entre as crianças. No final do estudo, o QI das crianças dos quatro grupos havia aumentado. As crianças que estavam no grupo com aulas de música tiveram um aumento de desempenho no teste de inteligência maior do que as crianças que estavam no grupo com aulas de teatro ou sem nenhuma aula. No entanto, esse aumento no teste de inteligência foi considerado pequeno.

Após os testes, os pais das crianças foram questionados sobre a duração da prática no teclado, e verificou-se que as crianças do grupo com aulas de teclado praticavam de dez a quinze minutos por semana. De qualquer forma, o melhor resultado do grupo com aulas de teclado poderia ter se originado da estrutura das aulas de música, a qual era diferente das aulas de teatro e das aulas de canto e poderia levar a melhores habilidades de fazer o teste.

Embora as aulas de música causem pequenos aumentos no QI, como mostrou a pesquisa experimental de Schellenberg (2004), a maioria das pesquisas sobre aulas de música e habilidades cognitivas, provenientes de estudos quase-experimentais e correlacionais, é consistente com a visão de 
que crianças com alto QI são mais propensas a terem aulas de música. Os estudos quase-experimentais comparam crianças ou adultos, os quais são organizados em grupos baseados em diferenças que já existem, como se tiveram ou não aulas de música ou se são músicos ou não. Os estudos correlacionais examinam se duas ou mais variáveis, como duração das aulas de música e habilidades intelectuais, aumentam ou diminuem quando são comparadas (Swaminathan; Schellenberg, 2014).

Porém, essas duas interpretações (de um lado, os estudos experimentais, de outro, os estudos quase-experimentais e correlacionais) não são excludentes. As crianças que têm um alto funcionamento podem ser mais propensas a terem aulas de música, mas as aulas de música podem aumentar ainda mais as vantagens cognitivas que já existem (Swaminathan; Schellenberg, 2014).

Pelo fato de as aulas de música causarem pequenos aumentos na inteligência, poderíamos ser levados a pensar que os músicos profissionais poderiam ser gênios. Contudo, quando músicos profissionais são comparados com indivíduos sem treinamento musical, a associação entre o aumento da inteligência e as aulas de música frequentemente desaparece. Ou seja, as associações entre habilidades cognitivas gerais e treinamento musical estão mais relacionadas com as aulas de música na infância do que com músicos profissionais (Schellenberg; Weiss, 2013).

Além de as aulas de música causarem pequenos aumentos na inteligência, Costa-Giomi (2012a) observa que há pouca evidência que apoie a ideia de que os beneficios intelectuais associados com as aulas de música sejam de longa duração. Estudos realizados pela autora mostram que estudar música por um ano, por exemplo, de fato aumenta o desempenho em tarefas de habilidades cognitivas. Entretanto, os resultados dos estudos indicam que esse aumento é pequeno e temporário. O aumento nos testes de habilidades cognitivas não tem duração superior a dois anos.

Costa-Giomi (2012b) apresenta o estudo experimental longitudinal que foi realizado com 117 crianças que tiveram aulas de piano por três anos, as quais foram colocadas em dois grupos de forma aleatória, e teve como objetivos verificar os efeitos de longo prazo das aulas de música nas habilidades cognitivas, autoestima e desempenho acadêmico de crianças. O primeiro grupo recebeu aulas de piano, enquanto o segundo grupo não participou das aulas de música.

Os resultados do estudo mostraram que as aulas de piano tiveram efeitos de curto prazo nas habilidades cognitivas, especialmente nas habilidades espaciais, mas não tiveram efeitos de longo prazo. Embora as crianças do grupo das aulas de música tenham tido uma maior pontuação nos testes de habilidades cognitivas durante os dois primeiros anos, quando comparadas com as crianças do grupo que não teve aula, não houve diferenças no desempenho cognitivo entre os dois grupos no final do terceiro ano. Além disso, após as aulas de piano terem encerrado, o desempenho dos 
dois grupos nos testes de memória e inteligência foram iguais (Costa-Giomi, 2012b).

No estudo desenvolvido por Kaviani et al. (2014), um grupo de crianças recebeu três meses de aulas semanais de música e obteve ganhos no pósteste estatisticamente significativos em uma versão padronizado do teste de QI Stanford-Binet. Não houve evidência de melhora no grupo-controle, aquele que não recebeu aulas de música. Entretanto, não foi possivel atribuir os resultados positivos ao grupo que recebeu aulas de música, uma vez que outros aspectos da intervenção, como, por exemplo, o contato com o professor, poderiam ter influenciado os resultados.

De acordo com Schellenberg (2016), as associações positivas entre aulas de música e habilidades cognitivas em geral podem ser consequência de uma melhor memória ou um funcionamento executivo superior, os quais produzem um melhor desempenho em uma grande variedade de testes, incluindo os testes de inteligência. Há evidências que mostram que o aumento de habilidades auditivas de indivíduos treinados musicalmente se estende também para testes que envolvem memória para estímulos auditivos.

Pessoas com treinamento musical geralmente têm melhor desempenho na memória tanto para estímulos auditivos quanto para estímulos visuais. Geralmente o desempenho nas tarefas auditivas é melhor do que nas tarefas visuais porque os indivíduos treinados musicalmente são bons ouvintes. Entretanto, é possível que diferenças existentes anteriormente nos indivíduos determinem uma melhor memória no decorrer do processo de desenvolvimento, assim como quem terá aulas de música.

As funções executivas representam habilidades gerais, como flexibilidade cognitiva, planejamento e habilidade para ignorar informações irrelevantes ou inibir respostas automáticas incorretas. Indivíduos treinados musicalmente geralmente têm melhor desempenho em alguns testes de funções executivas, principalmente nos testes que exigem atenção seletiva e inibição de respostas, mas há pouca evidência de que o treinamento musical cause aumento na memória ou no funcionamento executivo (Schellenberg, 2016).

\section{CONSIDERAÇÕES FINAIS}

Há bastante interesse na relação entre música, saúde e bem-estar. Diversas áreas têm desenvolvido estudos para verificar a extensão dos benefícios da música, como musicoterapia, música comunitária, uso da música no dia a dia, música na medicina e educação musical.

Vimos que podem ser estabelecidas algumas associações entre as aulas de música e melhorias no desempenho de habilidades cognitivas específicas, como a percepção da fala, habilidades de linguagem, habilidades espaciais e habilidades matemáticas. Porém, é possivel que alguma habilidade musical que esteja presente desde o nascimento possa ter influência na percepção da 
fala de quem estuda música. Não está claro se podemos fazer generalizações de resultados de pesquisas sobre melhora no desempenho de habilidades de linguagem depois das aulas de música. Indivíduos com melhor desempenho em habilidades espaciais e habilidades matemáticas podem ser mais propensos a terem aulas de música, e isso poderia ter influência nos resultados dos estudos que mostram que as aulas de música melhoraram o desempenho nos testes dessas habilidades.

Em relação às habilidades cognitivas gerais, como QI, memória e funções executivas, há poucas evidências de que aulas de música causem aumento na memória ou no funcionamento executivo. Os estudos experimentais mostram que estudar música durante a infância produz benefícios intelectuais, mas esses beneficios são pequenos aumentos no QI, cuja duração é temporária, ou seja, seus efeitos duram, no máximo, dois anos.

É importante conhecermos e pesquisarmos ainda mais sobre os benefícios da música e, principalmente, a relação entre aulas de música e habilidades cognitivas não musicais. No entanto, ainda não podemos afirmar que estudar música deixa alguém mais inteligente. As aulas de música trazem alguns benefícios cognitivos que ainda são questionados ou não têm uma longa duração. O mais relevante é compreender que as aulas de música trazem beneficios às habilidades cognitivas musicais. As aulas de música estão associadas de forma positiva tanto com habilidades na performance musical quanto às habilidades de ouvir música, tais como melhor discriminação dos sons, aumento da memória para música familiar e não familiar, melhor identificação de melodias, melhor processamento auditivo (Schellenberg, 2015).

Ilari (2009) observa que é necessário ter cautela antes de afirmar que uma criança é mais inteligente que outra, porque toca algum instrumento musical, ou ao colocar uma criança de apenas quatro anos para estudar violino com o objetivo de torná-la mais inteligente. O que é certo é que aprender música torna as crianças mais inteligentes musicalmente falando. O principal argumento para o ensino de música não são os benefícios cognitivos não musicais, mas os beneficios cognitivos musicais, a inteligência musical.

De acordo com Gardner (1995), a inteligência musical baseia-se no reconhecimento de padrões tonais, através da apreciação, composição ou reprodução de uma obra musical. Antunes (2002) define inteligência musical como a capacidade de percepção, identificação, classificação de sons diferentes, intensidade, direção, andamento, tons, melodias, frequência, timbre, estilos, dentre outros.

Os achados dos estudos sobre aulas de música e habilidades não musicais que mostram que os beneficios intelectuais das aulas de música são apenas temporários têm importantes implicações para a educação das crianças, pois justificar a existência de um programa de educação musical 
com base em tais beneficios parece ser uma campanha enganosa e ineficaz (Costa-Giomi, 2012a).

\section{REFERENCIAS}

ANTUNES, Celso. As inteligências múltiplas e seus estimulos. Campinas: Papirus, 2002.

BARCELLOS, Lia Rejane Mendes. Quaternos de musicoterapia e coda. Dallas: Barcelona Publishers, 2016.

BRANDLER, Susan; RAMMSAYER, Thomas. Differences in mental abilities between musicians and non-musicians. Psychology of music, 31, p. 123138, 2003. Disponivel em:

http://pom.sagepub.com/content/31/2/123.abstract. Acesso em: 28 out. 2016.

BRUSCIA, Kenneth E. Definindo musicoterapia. Tradução Mariza Velloso Fernandez Conde. 2. ed. Rio de Janeiro: Enelivros, 2000.

CHOBERT, Julie; MARIE, Céline; FRANCOIS, Clément; SCHÖN, Daniele; BESSON, Mireille. Enhanced passive and active processing of syllables in musician children. Journal of cognitive neuroscience, v. 23, p. 3874-3887, 2011. Disponivel em: https://www.ncbi.nlm.nih.gov/pubmed/21736456. Acesso em: 28 out. 2016.

COSTA-GIOMI, Eugenia. Music instruction and children's intellectual development: the educational context of music participation. In:

MACDONALD, Raymond; KREYTZ, Gunter; MITCHELL, Laura (Eds.). Music, health, \& wellbeing. New York: Oxford University Press, 2012a. p. 339-355.

. Music education and intellectual development in children: historical, research, and educational perspectives. In: SIMPÓSIO BRASILEIRO DE PÓS-GRADUANDOS EM MÚSICA, 2., 2012, Rio de Janeiro. Anais [...]. Rio de Janeiro: Unirio, 2012b, p. 21-36. Disponivel em:

http://www.seer.unirio.br/index.php/simpom/article/viewFile/2601/1929. Acesso em: 29 out. 2016.

CREECH, Andrea; HALLAM, Susan; GAUNT, Helena; PINCAS, Anita; MCQUEEN, Hilary; VARVARIGOU, Maria. The power of music in the lives of older adults. Research Studies in Music Education, v. 35, n. 1, p. 83-98, 2013. Disponivel em:

https://www.researchgate.net/publication/258183735_The_power_of_musi c_in_the_lives_of_older_adults. Acesso em: 8 abr. 2016.

DABBACK, William M.; SMITH, David S. Elders and music: empowering learning, valuing life experience, and considering the needs of aging adult learners. In: MCPHERSON, Gary E.; WELCH, Graham F. (Eds.). The Oxford Handbook of Music Education. Vol. II. New York: Oxford University Press, 2012. p. 229-242. 
FORGEARD, Marie; WINNER, Ellen; NORTON, Andrea; SCHLAUG, Gottfried. Practicing a musical instrument in childhood is associated with enhanced verbal ability and nonverbal reasoning. PLoS one, v. 3, n. 10, 2008.

Disponivel em: https://www.ncbi.nlm.nih.gov/pubmed/18958177. Acesso em: 28 out. 2016.

GARDNER, Howard. Inteligências múltiplas: a teoria na prática. Porto Alegre: Artmed, 1996.

HAIMSON, Jennifer; SWAIN, Deanna; WINNER, Ellen. Are mathematicians more musical than the rest of us? Music perception, v. 29, n. 2, p. 203-213, 2011. Disponivel em:

http://boots.bc.edu/islandora/object/bcir:100756/datastream/PDF/downl oad/citation.pdf. Acesso em: 28 out. 2016.

HALLAM, Susan. Music education: the role of affect. In: JUSLIN, Patrik N.; SLOBODA, John. Music and emotion: theory, research, applications. New York: Oxford University Press, 2010. p. 791-817.

HENTSCHKE, Liane; DEL BEN, Luciana. Aula de música: do planejamento e avaliação à prática educativa. In: HENTSCHKE, Liane; DEL BEN, Luciana (Orgs.). Ensino de música: propostas para pensar e agir em sala de aula. São Paulo: Moderna, 2003.

ILARI, Beatriz. Música na infância e na adolescência: um livro para pais, professores e aficionados. Curitiba: Ibpex, 2009.

KAVIANI, Hossein; MIRBAHA, Hilda; POURNASEH, Mehrangiz; SAGAN, Olivia. Can music lessons increase the performance of preschool children in IQ tests? Cognitive Processing, v. 15, n. 1, p. 77-84, 2014. Disponivel em: https://www.ncbi.nlm.nih.gov/pubmed/23793255. Acesso em: 6 fev. 2019.

LEINIG, Clotilde Espinola. Tratado de musicoterapia. São Paulo: Sobral Editora Técnica Artesgráficas, 1977.

MACDONALD, Raymond; KREUTZ, Gunter; MITCHELL, Laura. What is music, health, and wellbeing and why is it important? In: MACDONALD, Raymond; KREUTZ, Gunter; MITCHELL, Laura. Music, healthy, \& wellbeing. Oxford: Oxford University Press, 2012. p. 4-11.

MACDONALD, Raymond. Music, health, and well-being: a review. International Journal of Qualitative Studies on Health and Well-being, n. 8, 2013. Disponivel em:

http://www.ncbi.nlm.nih.gov/pmc/articles/PMC3740599/. Acesso em: 31 jul. 2013.

MOURA COSTA, Clarice. O despertar para o outro. São Paulo: Summus Editorial, 1989.

RAUSCHER, Frances H.; HINTON, Sean C. Music instruction and its diverse extra-musical benefits. Music perception, v. 29, p. 215-226, 2011. Disponivel 
em: http://mp.ucpress.edu/content/29/2/215.full.pdf+html. Acesso em: 28 out. 2016.

SCHELLENBERG, E. Glenn. Music lessons enhance IQ. Psychological science, v. 15, n. 511, p. 511-514, 2004. Disponivel em: http:/ /www.utm.utoronto.ca/ w3psygs / FILES/SchellenbergPS2004.pdf. Acesso em: 29 out. 2016.

. Music and nonmusical abilities. In: MCPHERSON, G. E. (Ed.). The child as musician: a handbook of musical development. 2. ed. New York: Oxford University Press, 2015. p. 149-176. Disponivel em:

http:/ / www.utm.utoronto.ca/ w3psygs / FILES/Schellenberg2015Chapter.p df. Acesso em: 11 abr. 2016.

Music training and nonmusical abilities. In: HALLAM, Susan; CROSS, Ian; THAUT, Michael (Eds.). The Oxford handbook of music psychology. 2. ed. New York: Oxford University Press, 2016. p. 415-429.

SCHELLENBERG, E. Glenn.; WEISS, Michael W. Music and cognitive abilities. In: DEUTSCH, D. (Ed.). The psychology of music. 3. ed. Amsterdam: Elsevier, 2013. p. 499-550. Disponivel em:

http:/ / www.erin.utoronto.ca/ w3psygs / SchellenbergWeissPoM.pdf. Acesso em: 31 jul. 2013.

STRAIT, Dana L.; KRAUS, Nina. Biological impact of auditory expertise across the life span: musicians as a model of auditory learning. Hearing research, v. 308, p. 109-121, 2014. Disponivel em:

https://www.ncbi.nlm.nih.gov/pmc/articles/PMC3947192/. Acesso em: 28 out. 2016.

SWAMINATHAN, Swathi; SCHELLENBERG, E. Glenn. Music training and cognitive abilities: associations, causes, and consequences. In: THAUT, Michael H.; HODGES, Donald A. (Eds.). The Oxford handbook of music and neuroscience. New York: Oxford University Press, 2018. Disponivel em: https://www.utm.utoronto.ca/ w3psygs/FILES/SwaminathanSchellenberg 2018.pdf. Acessado em: 5 fev. 2019.

WILLIAMSON, Victoria. You are the music: how music reveals what it means to be human. London: Icon Books, 2014. 
José Davison da Silva Júnior é Licenciado em Música pela Universidade Federal de Pernambuco e Bacharel em Direito pela Faculdade de Direito de Olinda. Especialista em Musicoterapia pelo Conservatório Brasileiro de Música e em Educação Especial pela Faculdade Frassinetti do Recife. É Mestre em Música pela Universidade Federal de Goiás e Doutor em Música pela Universidade Federal da Bahia, com Programa Doutorado Sanduíche realizado no Center for Mind Brain - University of California, Davis. Pós-doutor pelo Programa de Pós-Graduação em Neurociência e Cognição da Universidade Federal do ABC. https://orcid.org/0000-0001-9160-0658 